\title{
Interpreting biomarker data from the COPHES/DEMOCOPHES twin projects: Using external exposure data to understand biomarker differences among countries
}

\author{
R. Smolders ${ }^{\text {a,* }}$, E. Den Hond ${ }^{a}$, G. Koppen ${ }^{a}$, E. Govarts ${ }^{a}$, H. Willems ${ }^{a}$, L. Casteleyn ${ }^{\text {b }}$,
} M. Kolossa-Gehring ${ }^{c}$, U. Fiddicke ${ }^{c}$, A. Castaño ${ }^{d}$, H.M. Koch ${ }^{\mathrm{e}}$, J. Angerer ${ }^{\mathrm{e}}$, M. Esteban ${ }^{\mathrm{d}}$, O. Sepai ${ }^{f}$, K. Exley ${ }^{f}$, L. Bloemen ${ }^{g}$, M. Horvat ${ }^{\text {h }}$, L.E. Knudsen ${ }^{i}$, A. Joas ${ }^{j}$, R. Joas ${ }^{j}$, P. Biot ${ }^{k}$, D. Aerts ${ }^{k}$, A. Katsonouri ${ }^{1}$, A. Hadjipanayis ${ }^{m}$, M. Cerna ${ }^{n}$, A. Krskova ${ }^{n}$, G. Schwedler ${ }^{c}$, M. Seiwert ${ }^{\mathrm{c}}$, J.K.S. Nielsen ${ }^{\mathrm{i}}$, P. Rudnai ${ }^{\circ}$, S. Közepesy ${ }^{\circ}$, D.S. Evans ${ }^{\mathrm{p}}$, M.P. Ryan ${ }^{\mathrm{q}}$, A.C. Gutleb ${ }^{\mathrm{r}}$, M.E. Fischer ${ }^{\mathrm{s}}$, D. Ligocka ${ }^{\mathrm{t}}$, M. Jakubowski ${ }^{\mathrm{t}}$, M.F. Reis ${ }^{\mathrm{u}}$, S. Namorado ${ }^{\mathrm{u}}$, I.-R. Lupsa ${ }^{\mathrm{v}}$, A.E. Gurzau v ${ }^{\text {, K. Halzlova }}{ }^{\text {w }}$, E. Fabianova ${ }^{w}$, D. Mazej ${ }^{\text {h }}$, J. Tratnik Snoj ${ }^{\text {h }}$, S. Gomez ${ }^{\text {d }}$, S. González ${ }^{\mathrm{d}}$, M. Berglund ${ }^{\mathrm{x}}$, K. Larsson ${ }^{\mathrm{x}}$, A. Lehmann ${ }^{\mathrm{y}}$, P. Crettaz ${ }^{\mathrm{y}}$, G. Schoeters ${ }^{\mathrm{a}, \mathrm{z} \text {,aa }}$

${ }^{a}$ Flemish Institute of Technological Research (VITO), Environmental Risks and Health Unit, Boeretang 200, 2400 Mol, Belgium

${ }^{\mathrm{b}}$ KU LEUVEN, Belgium

${ }^{\mathrm{c}}$ Federal Environment Agency (UBA), Germany

d Instituto de Salud Carlos III, Spain

e Institute for Prevention and Occupational Medicine of the German Social Accident Insurance - Institute of the Ruhr-Universität Bochum (IPA), Germany

${ }^{\mathrm{f}}$ Public Health England, United Kingdom

${ }^{\mathrm{g}}$ Environmental Health Sciences International, The Netherlands

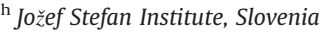

i University of Copenhagen, Denmark

${ }^{\mathrm{j}}$ BiPRO, Germany

${ }^{\mathrm{k}}$ FPS Health, Food Chain Safety and Environment, Belgium

${ }^{1}$ State General Laboratory, Ministry of Health, Cyprus

${ }^{\mathrm{m}}$ Larnaca General Hospital, Ministry of Health, Cyprus

${ }^{\mathrm{n}}$ National Institute of Public Health, Czech Republic

${ }^{\circ}$ National Institute of Environmental Health, Hungary

${ }^{\mathrm{p}}$ Health Service Executive (HSE), Ireland

${ }^{\mathrm{q}}$ University College Dublin (UCD), Ireland

${ }^{\mathrm{r}}$ Centre de Recherche Public - Gabriel Lippmann, Luxembourg

${ }^{s}$ Laboratoire Nationale de Santé, Luxembourg

${ }^{\mathrm{t}}$ Nofer Institute of Occupational Medicine, Poland

"Faculdade de Medicina de Lisboa, Portugal

${ }^{v}$ Environmental Health Center, Romania

w Úrad verejného zdravotníctva Slovenskej republiky, Slovakia

${ }^{x}$ Karolinska Institutet, Sweden

${ }^{y}$ Federal Office of Public Health (FOPH), Switzerland

${ }^{\mathrm{z}}$ University of Antwerp, Belgium

aa Southern Denmark University, Odense, Denmark

\section{A R T I C L E I N F O}

\section{Article history:}

Received 20 May 2014

Received in revised form

13 August 2014

Accepted 14 August 2014

\begin{abstract}
A B S T R A C T
In 2011 and 2012, the COPHES/DEMOCOPHES twin projects performed the first ever harmonized human biomonitoring survey in 17 European countries. In more than 1800 mother-child pairs, individual lifestyle data were collected and cadmium, cotinine and certain phthalate metabolites were measured in urine. Total mercury was determined in hair samples. While the main goal of the COPHES/DEMOCOPHES twin projects was to develop and test harmonized protocols and procedures, the goal of the current paper is to investigate whether the observed differences in biomarker values among the countries
\end{abstract}

\footnotetext{
* Corresponding author.

E-mail address: roel.smolders@vito.be (R. Smolders).
} 
Keywords:

Human biomonitoring

Interpretation

COPHES

DEMOCOPHES

External exposure data implementing DEMOCOPHES can be interpreted using information from external databases on environmental quality and lifestyle.

In general, 13 countries having implemented DEMOCOPHES provided high-quality data from external sources that were relevant for interpretation purposes. However, some data were not available for reporting or were not in line with predefined specifications. Therefore, only part of the external information could be included in the statistical analyses. Nonetheless, there was a highly significant correlation between national levels of fish consumption and mercury in hair, the strength of antismoking legislation was significantly related to urinary cotinine levels, and we were able to show indications that also urinary cadmium levels were associated with environmental quality and food quality. These results again show the potential of biomonitoring data to provide added value for (the evaluation of) evidence-informed policy making.

(c) 2014 Elsevier Inc. All rights reserved.

\section{Introduction}

Collecting human biomonitoring (HBM) data of the general population fits into a strategy to protect public health by addressing potentially critical chemicals in the context of internal dose rather than external exposure concentrations. HBM offers an excellent approach to monitor aggregate and cumulative exposure to chemicals (Smolders et al., 2009; Pleil et al., 2011; Dong and Hu, 2012; Sarigiannis and Hansen, 2012). Despite the fact that HBM is a robust and realistic means of exposure assessment, it is not always straightforward to identify individual contributions of exposure sources and pathways. Therefore, when biomonitoring data is considered in isolation, it is often difficult to provide policy makers with information on which of the many exposure routes is/are predominantly related to internal dose (Paustenbach and Galbraith, 2006; Bevan et al., 2012; Sarigiannis and Hansen, 2012). At the same time, it has explicitly been shown that if HBM is combined with ambient monitoring and questionnaire data, exposure sources can be identified (e.g. Bilau et al., 2009; KolossaGehring et al., 2012; Cerna et al., 2012).

In order to assist in the interpretation of biomarker data, HBM studies often collect additional information outside of the sampling of blood, urine, or other biological matrices, mostly through questionnaires, and in some studies also by matching analyses of e.g. house dust, drinking water or indoor air contaminants. Through the selection of relevant questions, several important exposure determinants, including lifestyle factors (e.g. exposure to environmental tobacco smoke, alcohol consumption, diet, use of cosmetics, etc.), or occupational and environmental characteristics (e.g. living near specific emission sources, etc.) can be identified.

Other data from environmental quality monitoring programs are often available through different local, regional, national or international monitoring networks (i.e. outside of a specific HBM study), and can be considered additional, external sources of information (Smolders et al., 2007; Paustenbach and Galbraith, 2006). This paper focuses on this latter type of information sources to assist in the interpretation of some of the biomarkers that have been measured in the COPHES/DEMOCOPHES twin projects. While neither HBM nor environmental monitoring alone is sufficient to understand human exposure to chemicals, both are complementary pieces of the same exposure assessment puzzle.

Briefly, the COPHES project developed harmonized protocols for all aspects of HBM surveys, including recruitment, sampling, chemical analysis, quality assurance and control, data analysis, interpretation, and communication and dissemination. DEMOCOPHES provided the practical platform in which these harmonized protocols were subsequently adapted to fit national requirements, and were tested. A more extensive outline of both projects is described in detail in other papers in this issue, or can be found elsewhere (Becker et al., 2011; Joas et al., 2012). Apart from the harmonization aspect, a secondary goal of the COPHES/DEMOCOPHES twin projects, and the subject of this paper, was to investigate whether the observed differences in biomarker values among the countries implementing DEMOCOPHES could be interpreted using information from external databases on environmental quality and lifestyle.

Generally, the choice of biomarkers, matrix and identification of the study population in HBM studies is based on an a priori research question, and projects are designed in such a way that HBM data offer an optimal source of complementary information with regard to the research question. This type of research project often covers only a limited geographical area or a targeted (sub)population (e.g. pregnant women, children, etc.) with a relatively limited number of participants. Well-known recent examples in the literature include the use of HBM to evaluate the effect of fish consumption or amalgam fillings on biological measures of mercury exposure (Miklavčič et al., 2013, 2014; Karagas et al., 2012; Burger et al., 2005), the effect of banning leaded fuel on blood lead levels (Pino et al., 2004; Schnaas et al., 2004), or the effects of antismoking legislation on cotinine levels (Allwright et al., 2005; Sims et al., 2012).

At the same time, several large-scale population HBM surveys have emerged over the last decades across different European regions and countries, including Flanders (Schoeters et al., 2012), the Czech Republic (Cerna et al., 2012), Germany (Kolossa-Gehring et al., 2012), France (Frery et al., 2012), Spain (Pérez-Gómez et al., 2013; Esteban et al., 2013), and the USA (Calafat, 2012) and Canada (Haines and Murray, 2012). These large-scale survey studies are typically tailored to provide researchers and policy makers with a general picture of the distribution of internal levels of chemicals among the general population. They are also used to establish reference values. Hence they are set up to be country or region representative. They often include a wide variety of biomarkers, and aim to provide periodical measurements of the prevalence of exposure to environmental agents. Although the DEMOCOPHES study in itself was a pilot project for an EU-wide HBM monitoring study, and hence is not directly comparable to the national survey studies mentioned above, the COPHES/DEMOCOPHES twin projects shared the same targets at an overarching European level.

In order to assist in interpreting the findings of large-scale population HBM surveys, two distinct types of data on exposure sources and pathways can be collected:

- Individual information: HBM surveys generally include completing a questionnaire, in which person-specific information regarding the occupation, socio-economic status, living conditions, consumption behavior, etc. of the participants is collected. As this type of information relates to the individual's exposure profile, it is very relevant in the interpretation of an individual's biomarker profile as well (Bilau et al., 2009; Haug et al., 2011; Johansson et al., 2005).

- External information: At a European level, several of the environmental quality data collections are managed and harmonized by European or international organisations, including the European 
Environmental Agency (EEA), the European Food Safety Authority (EFSA), or the World Health Organization (WHO). These data serve different purposes such as compliance with legislation, policy support, or trend analysis, and may also contain valuable information to aid in interpreting biomarker data.

The goal of the current paper was to investigate whether the observed differences in biomarker values among the countries implementing DEMOCOPHES could be interpreted using information from these external databases on environmental quality and lifestyle. Throughout our study, an additional distinction was made between two types of external monitoring data:

- (Sub)national datasets: Many countries in Europe and globally have ongoing environmental monitoring programs to collect data on the quality of various environmental compartments (air, water, soil, etc.). Often these monitoring programs are a legal requirement (e.g. to report data to Eurostat or the European Environment Agency), yet sometimes they are also developed to fit local policy needs. These (sub)national datasets frequently have distinct properties: (i) they are generally available at a relatively small geographical scale, (ii) harmonization of standard operating procedures (SOPs), monitoring setups, reporting mechanisms, may vary among countries and (iii) local and (sub)national data may primarily be focused on internal use, are often only available in gray literature, and hence not easily retrievable by outsiders.
- Aggregate EU-collected datasets: There are various harmonized data collections addressing different aspects of environmental quality and health determinants across Europe by EEA, EFSA, WHO, etc. For example, EEA offers information on environmental indicators derived from harmonized environmental monitoring campaigns (e.g. Foregs, Airbase), or emissions from industrial facilities (e.g. E-PRTR). Similarly, EFSA collects data of chemicals in different food items as well as food consumption data in support of European policy making.

A generic overview of the structure of the current study, embedded in the COPHES/DEMOCOPHES projects, is provided in Fig. 1.

\section{Materials and methods}

\subsection{Collection of external data}

As the COPHES/DEMOCOPHES twin projects were specifically designed to provide and test harmonized protocols for large-scale HBM surveys, only wellknown relationships between exposure sources and biomarkers were included in our study (Table 1). No specific topics were included that required collecting additional information on phthalate biomarkers, as the sources of phthalate exposure and/or their potential health effects are still insufficiently understood or supported by external data to warrant the collection of external data.

For the (sub)national datasets, the national focal points of the countries that participated in DEMOCOPHES were provided with guidelines on which type of external data needed to be collected (marked ND in Table 1). Smolders et al. (2012) described the rationale behind this, and in which format the data needed to be reported. During a COPHES/DEMOCOPHES training workshop held in Copenhagen, Denmark (March 2012),

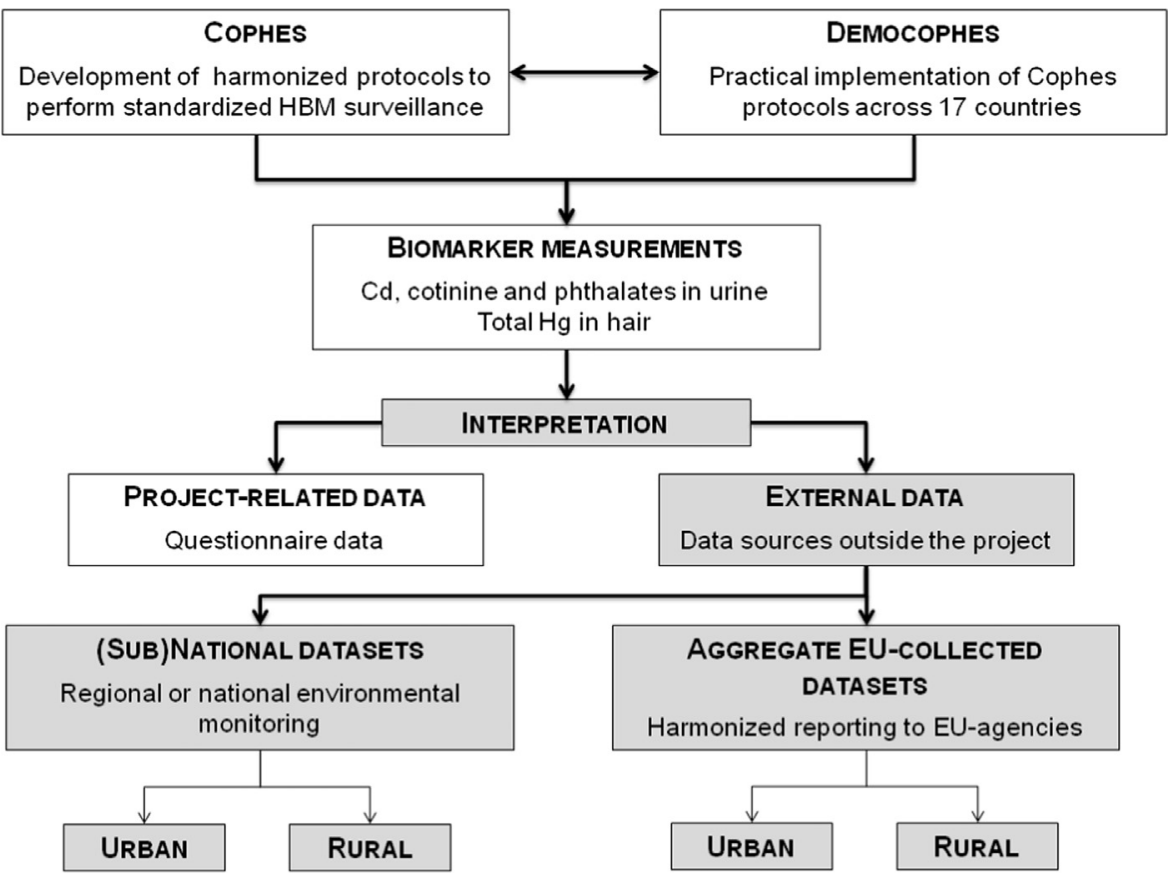

Fig. 1. Generic overview of the relationship between the current study (shaded) and the COPHES/DEMOCOPHES twin projects.

Table 1

An overview of the selected interpretation topics using either the (sub)national datasets (ND) or aggregate EU-collected data (EU).

\begin{tabular}{|c|c|c|c|}
\hline & Cadmium & Mercury & Cotinine \\
\hline \multicolumn{4}{|l|}{ Are differences in environmental concentrations able to explain differences in biomarker values? } \\
\hline Air & $\mathrm{ND} / \mathrm{EU}$ & ND/EU & \\
\hline Water (drinking/surface) & ND & ND & \\
\hline Food (for mercury specifically aquatic food products) & $\mathrm{ND} / \mathrm{EU}$ & $\mathrm{ND} / \mathrm{EU}$ & \\
\hline Soil & $\mathrm{ND} / \mathrm{EU}$ & ND & \\
\hline Does anti-smoking legislation and banning of smoking in public places affects biomarker values of non-smokers? & $\mathrm{ND} / \mathrm{EU}$ & & $\mathrm{ND} / \mathrm{EU}$ \\
\hline Are regional emission data useful to improve the interpretation of biomarker values? & EU & EU & \\
\hline
\end{tabular}


representatives from the different countries participating in DEMOCOPHES received further instructions. To facilitate reporting, an excel-template was prepared in which all the requested data could be stored under a harmonized format.

At the same time, EU data were aggregated to investigate whether these data could assist in interpreting inter-national differences in biomarker measurements (indicated as EU in Table 1). Table 2 provides an overview of the aggregated EU-collected datasets consulted.

\subsection{Biomarker data}

The national biomarker data from the DEMOCOPHES field study are summarized in Table 3. These data are not adjusted for factors such as age, smoking behavior, and other potentially confounding factors. The systematic approach for the design and conduct of this EU-wide cross-sectional human biomonitoring (HBM) study and for the implementation of the fieldwork procedures has been described elsewhere (Becker et al. 2014, other papers in this issue).

All statistical analyses were performed using GraphPad Prism 5 Software for Windows. As the number of data points generally was low, only robust nonparametric statistical techniques were used. To calculate correlations among different datasets, Spearman's rank correlation coefficient was used. To compare different groups, the Kruskal-Wallis test was used, followed by Dunn's Multiple Comparison Test. Throughout all the analyses, a significance level of 0.05 was used. However, as the project used heterogeneous datasets, analyses with $p$-values between 0.05 and 0.10 are reported as being borderline significant.

\section{Results and discussion}

\subsection{Collection of (sub)national datasets by DEMOCOPHES countries}

An overview of the external data provided by different DEMOCOPHES countries is provided in Table 4. Most DEMOCOPHES countries collected and report a good amount of high quality data from (sub)national datasets, following the guidelines and reporting format outlined in the Copenhagen training workshop. At the same time, four out of 17 countries participating in the DEMOCOPHES study failed to provide the external data requested, which obviously reduced the power of the subsequent statistical analyses. In addition, some countries only provided partial datasets, or provided information which could not be used in the statistical analyses (e.g. reporting that "no data are available").

\subsection{External data to aid in interpreting urinary cadmium}

\subsubsection{Interpreting urinary cadmium from (sub)national datasets}

To aid in interpreting the potential differences in cadmium content in urine from DEMOCOPHES, national focal points were asked to collect information on the presence of cadmium in air, water and soil as potential exposure sources, and in various food items which are known to have a risk for high cadmium concentrations per gram wet weight or to contribute considerably to the daily dietary cadmium intake (EFSA, 2009; Vromman et al., 2010). However the correlation between urinary cadmium concentrations for mothers and children and cadmium concentrations in the various environmental compartments (air, drinking and surface water, soil) was not statistically significant. With regard to the collection of data to interpret the potential contribution of food items, both food quality (cadmium concentrations in various food items) and dietary intake of specific food items known to

Table 2

Overview of the publications and online databases used to collect EU-aggregated data.

\begin{tabular}{|c|c|c|}
\hline Biomarker & Compartment & Data source \\
\hline \multirow[t]{7}{*}{ Cadmium } & Air & CEIP database, available via: http://webdab1.umweltbundesamt.at/official_country_year.html?cgiproxy_skip=1 \\
\hline & Food & EFSA-report (2009), available at: http://www.efsa.europa.eu/en/efsajournal/doc/980.pdf \\
\hline & & EFSA-report (2012), available at: http://www.efsa.europa.eu/en/efsajournal/doc/2551.pdf \\
\hline & Soil & FOREGS database, available via: http://eusoils.jrc.ec.europa.eu/foregshmc/ \\
\hline & Anti-smoking & DG-Sanco database, available at: http://ec.europa.eu/health/tobacco/docs/tobacco_overview2011_en.pdf \\
\hline & legislation & Smokefree Partnership database, available at: http://www.smokefreepartnership.eu/smokefreemap \\
\hline & Regional emission data & E-PRTR-database, available at: http://prtr.ec.europa.eu/ \\
\hline \multirow[t]{4}{*}{ Mercury } & Air & EMEP database, available via: http://www.ceip.at/webdab-emission-database/gridded-emissions-in-google-maps \\
\hline & Fish & FAO-database, available at: http://faostat.fao.org/site/610/DesktopDefault.aspx?PageID=610 \\
\hline & & $\begin{array}{l}\text { SCOOP-report, available at: http://ec.europa.eu/food/food/chemicalsafety/contaminants/scoop_3-2-11_heavy_metals_report_en. } \\
\text { pdf }\end{array}$ \\
\hline & Regional emission data & E-PRTR-database, available at: http://prtr.ec.europa.eu/ \\
\hline \multirow[t]{2}{*}{ Cotinine } & Anti-smoking & DG-Sanco database, available at: http://ec.europa.eu/health/tobacco/docs/tobacco_overview2011_en.pdf \\
\hline & legislation & Smokefree Partnership database, available at: http://www.smokefreepartnership.eu/smokefreemap \\
\hline
\end{tabular}

Table 3

Overview of the geometric mean of unadjusted biomarker data (95\% confidence interval) of the DEMOCOPHES field study (Den Hond et al., 2012).

\begin{tabular}{|c|c|c|c|c|c|c|}
\hline & \multicolumn{2}{|c|}{ Cadmium (in $\mu \mathrm{g} / \mathrm{g}$ creatinine) } & \multicolumn{2}{|c|}{ Mercury (in $\mu \mathrm{g} / \mathrm{g}$ hair) } & \multicolumn{2}{|c|}{ Cotinine (in $\mu \mathrm{g} / \mathrm{g}$ creatinine) } \\
\hline & Children & Mothers & Children & Mothers & Children & Mothers \\
\hline Belgium & $0.039(0.035-0.045)$ & $0.183(0.162-0.207)$ & $0.204(0.173-0.242)$ & $0.383(0.327-0.450)$ & $0.566(0.461-0.696)$ & $1.03(0.60-1.76)$ \\
\hline Switzerland & $0.073(0.065-0.083)$ & $0.196(0.173-0.221)$ & $0.077(0.065-0.091)$ & $0.163(0.139-0.191)$ & $0.487(0.396-0.598)$ & $0.73(0.43-1.26)$ \\
\hline Cyprus & $0.103(0.086-0.123)$ & $0.157(0.132-0.187)$ & $0.326(0.257-0.413)$ & $0.463(0.369-0.580)$ & $0.804(0.601-1.076)$ & $2.47(1.16-5.27)$ \\
\hline Czech Republic & $0.111(0.098-0.126)$ & $0.213(0.189-0.242)$ & $0.098(0.083-0.116)$ & $0.155(0.132-0.182)$ & $1.615(1.315-1.984)$ & $3.58(2.09-6.11)$ \\
\hline Germany & & & $0.055(0.047-0.065)$ & $0.113(0.096-0.133)$ & $0.280(0.228-0.344)$ & $0.81(0.48-1.39)$ \\
\hline Denmark & $0.022(0.020-0.025)$ & $0.118(0.104-0.134)$ & $0.249(0.211-0.295)$ & $0.420(0.358-0.493)$ & $0.679(0.553-0.835)$ & $1.57(0.92-2.68)$ \\
\hline Spain & $0.046(0.040-0.052)$ & $0.215(0.190-0.243)$ & $0.884(0.747-1.046)$ & $1.592(1.357-1.869)$ & $1.596(1.299-1.961)$ & $7.79(4.56-13.30)$ \\
\hline Hungary & $0.117(0.103-0.132)$ & $0.150(0.133-0.170)$ & $0.025(0.021-0.029)$ & $0.038(0.032-0.044)$ & 1.593 (1.297-1.957) & $6.40(3.75-10.92)$ \\
\hline Ireland & $0.061(0.054-0.069)$ & $0.268(0.237-0.303)$ & $0.097(0.082-0.114)$ & $0.165(0.141-0.194)$ & $0.659(0.537-0.810)$ & $3.28(1.92-5.60)$ \\
\hline Luxembourg & $0.143(0.120-0.171)$ & $0.215(0.180-0.256)$ & $0.180(0.142-0.228)$ & $0.416(0.332-0.522)$ & $0.390(0.292-0.522)$ & $0.50(0.24-1.08)$ \\
\hline Poland & $0.129(0.114-0.147)$ & $0.379(0.334-0.429)$ & $0.070(0.060-0.083)$ & $0.131(0.111-0.153)$ & 1.596 (1.299-1.961) & $6.08(3.56-10.38)$ \\
\hline Portugal & $0.044(0.039-0.050)$ & $0.161(0.143-0.183)$ & $1.035(0.875-1.225)$ & $1.203(1.025-1.412)$ & $1.194(0.972-1.466)$ & $9.15(5.36-15.63)$ \\
\hline Romania & $0.024(0.021-0.027)$ & $0.149(0.132-0.169)$ & $0.085(0.072-0.101)$ & $0.095(0.081-0.111)$ & $1.723(1.402-2.116)$ & 13.64 (7.99-23.29) \\
\hline Sweden & $0.088(0.077-0.099)$ & $0.139(0.123-0.157)$ & $0.181(0.153-0.214)$ & $0.260(0.222-0.305)$ & $0.224(0.183-0.276)$ & $1.58(0.92-2.69)$ \\
\hline Slovenia & $0.067(0.059-0.076)$ & $0.231(0.204-0.262)$ & $0.168(0.142-0.199)$ & $0.263(0.224-0.309)$ & $0.442(0.360-0.543)$ & $1.36(0.79-2.32)$ \\
\hline Slovak Republic & $0.123(0.108-0.139)$ & $0.239(0.211-0.271)$ & $0.092(0.078-0.109)$ & $0.129(0.110-0.152)$ & $0.911(0.742-1.119)$ & $2.43(1.43-4.16)$ \\
\hline United Kingdom & $0.160(0.141-0.181)$ & $0.234(0.207-0.265)$ & $0.193(0.163-0.228)$ & $0.163(0.139-0.192)$ & $0.712(0.580-0.875)$ & $0.68(0.40-1.16)$ \\
\hline
\end{tabular}


contribute to cadmium intake were included. However, no significant correlations were observed.

\subsubsection{Interpreting urinary cadmium from aggregate EU-collected datasets}

From the Centre of Emission Inventories and Projections (CEIP), hosted by the Austrian Umweltbundesamt, data on national emissions of cadmium in air were retrieved (see Table 2 for data source, Mareckova et al., 2012). Apart from Luxemburg, cadmiumemissions data for all countries participating in the DEMOCOPHES study could be retrieved from the WebDab-database. The most recent reporting for all other countries participating in DEMOCOPHES was from 2010. Although air emissions were not significantly correlated with urinary cadmium of children, a nearly significant relationship ( $r=0.50, p=0.059)$ was observed for air emissions of cadmium and urinary cadmium in mothers (Fig. 2).

This difference between the nearly-significant correlation in mothers and the total lack thereof in children may in part be due to the reflection of lifelong accumulated cadmium in the maternal urinary samples (Julin et al., 2011; Omarova and Philips, 2007; Tellez-Plaza et al., 2012), or by the fact that it is much more difficult to analyze the often very low levels of urinary cadmium in children.

Data on point sources of cadmium-emission to both air and water were collected from the European Pollutant Release and

Table 4

Overview of the external data provided by individual DEMOCOPHES countries.

\begin{tabular}{|c|c|c|c|c|c|c|c|c|c|}
\hline & \multicolumn{5}{|c|}{ Cadmium } & \multicolumn{3}{|c|}{ Mercury } & \multirow{2}{*}{$\begin{array}{l}\text { Cotinine } \\
\text { Smoking }\end{array}$} \\
\hline & Air & Water & Food & soil & Smoking & Air & Water & Fish & \\
\hline Country 1 & $\mathrm{X}$ & $\mathrm{X}$ & $\mathrm{X}$ & $\mathrm{X}$ & $\mathrm{X}$ & $\mathrm{X}$ & $\mathrm{X}$ & $\mathrm{X}$ & $\mathrm{X}$ \\
\hline Country 2 & $\mathrm{X}$ & $\mathrm{X}$ & $\mathrm{X}$ & $\mathrm{X}$ & $\mathrm{X}$ & $\mathrm{X}$ & $\mathrm{X}$ & $\mathrm{X}$ & $\mathrm{X}$ \\
\hline Country 3 & $\mathrm{X}$ & $\mathrm{X}$ & $\mathrm{X}$ & $\mathrm{X}$ & $\mathrm{X}$ & $\mathrm{X}$ & $\mathrm{X}$ & $\mathrm{X}$ & $\mathrm{X}$ \\
\hline Country 4 & $\mathrm{X}$ & $\mathrm{X}$ & $\mathrm{X}$ & $\mathrm{X}$ & $\mathrm{X}$ & $\mathrm{X}$ & $\mathrm{X}$ & $\mathrm{X}$ & $\mathrm{X}$ \\
\hline Country 5 & $\mathrm{X}$ & $\mathrm{X}$ & $\mathrm{X}$ & $\mathrm{X}$ & $\mathrm{X}$ & $(\mathrm{X})$ & $\mathrm{X}$ & $\mathrm{X}$ & $\mathrm{X}$ \\
\hline Country 6 & $\mathrm{X}$ & $\mathrm{X}$ & $\mathrm{X}$ & $\mathrm{X}$ & $\mathrm{X}$ & $(\mathrm{X})$ & $\mathrm{X}$ & $\mathrm{X}$ & $\mathrm{X}$ \\
\hline Country 7 & $\mathrm{X}$ & $\mathrm{X}$ & $\mathrm{X}$ & $\mathrm{X}$ & (X) & (X) & $\mathrm{X}$ & $(\mathrm{X})$ & (X) \\
\hline Country 8 & $\mathrm{X}$ & $\mathrm{X}$ & $\mathrm{X}$ & $(\mathrm{X})$ & $\mathrm{X}$ & (X) & $\mathrm{X}$ & $(\mathrm{X})$ & $\mathrm{X}$ \\
\hline Country 9 & $(\mathrm{X})^{\mathrm{a}}$ & $\mathrm{X}$ & $\mathrm{X}$ & $(\mathrm{X})$ & $\mathrm{X}$ & $(\mathrm{X})$ & $\mathrm{X}$ & $\mathrm{X}$ & $\mathrm{X}$ \\
\hline Country 10 & $\mathrm{X}$ & $\mathrm{X}$ & $\mathrm{X}$ & $\mathrm{X}$ & $\mathrm{X}$ & & $\mathrm{X}$ & $\mathrm{X}$ & $\mathrm{X}$ \\
\hline Country 11 & $\mathrm{X}$ & $\mathrm{X}$ & $\mathrm{X}$ & $\mathrm{X}$ & $(\mathrm{X})$ & & $\mathrm{X}$ & $\mathrm{X}$ & $(\mathrm{X})$ \\
\hline Country 12 & & $(\mathrm{X})$ & & $(\mathrm{X})$ & $\mathrm{X}$ & & & $\mathrm{X}$ & $\mathrm{X}$ \\
\hline Country 13 & $\mathrm{X}$ & $\mathrm{X}$ & $\mathrm{X}$ & $\mathrm{X}$ & & & $\mathrm{X}$ & $\mathrm{X}$ & \\
\hline
\end{tabular}

For marks between brackets $(\mathrm{X})$, reports indicated that a search was performed but no data could be reported for various reasons (not available, not yet published, not measured, etc.).
Transfer Register (E-PRTR) database for both the urban and rural region at NUTS-2 level (NUTS: Nomenclature of territorial units for statistics, NUTS-2 refers to basic regions for the application of regional policies). For each of the 28,000 industrial facilities included in the database, information is provided concerning the economic activity, amounts of pollutant releases to air, water and land as well as off-site transfers of waste and of pollutants in waste water from a list of 91 key pollutants including heavy metals, pesticides, greenhouse gases and dioxins. However, no significant correlations between E-PRTR data on annual emissions and urinary cadmium for children or mothers were found.

\subsubsection{Lifestyle factors and diet as an important source of cadmium}

For the countries participating in DEMOCOPHES, national data on the contribution of diet to the exposure to cadmium were taken from the European Food Safety Authority (EFSA) opinion on "Cadmium in food" and from the recent EFSA-report "Cadmium dietary exposure in the European population" (EFSA, 2009, 2012a). From the first report (EFSA, 2009), an overview of the most important food items that contribute to the cadmium intake could be generated, based on the calculations from the concise database which includes 15 food groups. In this report, data on both the importance of different food items in the everyday menu and on average cadmium-concentrations per food item were collected, and a mean and high-exposure cadmium uptake from summed food items was calculated. For 8 countries having implemented the DEMOCOPHES study, these data were available. Although there were no significant correlations between cadmium intake through summed food items and the urinary cadmium data for children, a nearly significant relationship between the high-exposure food uptake scenario and urinary cadmium in mothers was observed $(r=0.71, p=0.058)$. In the more recent EFSA-assessment on the dietary exposure of the European population to cadmium (EFSA, 2012a), data on dietary intake of cadmium were estimated for different age groups, including children and adults. Results of 5 or 7 different national dietary exposure assessments from EFSA's Comprehensive European Food Consumption Database were available for respectively children and adults. However, these data were not significantly correlated with the urinary cadmiumconcentrations in mothers and children, possibly because of the limited number of countries for which these data were available.

It has frequently been shown that dietary cadmium uptake indeed is a major uptake source in the non-smoking population, and can reasonably predict urinary cadmium levels (e.g. Julin et al., 2011; Jarup and Akesson, 2009). Unfortunately however, the available EFSA-database does not include all sampling areas

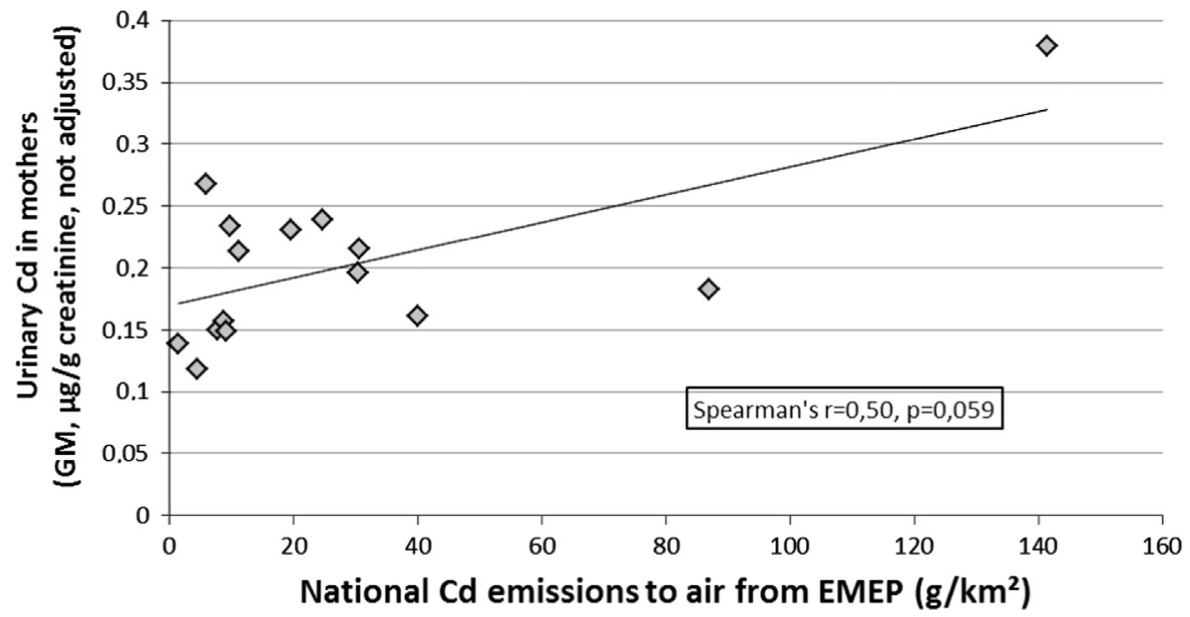

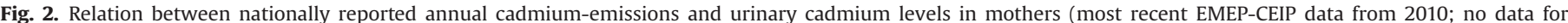
Luxemburg). 
covered by the DEMOCOPHES HBM investigations, and an estimate of the dietary cadmium uptake was only available for less than half of the DEMOCOPHES countries. Even for this small number of countries the statistical correlation between maternal urinary cadmium and the high-exposure food uptake scenario was nearly significant, indicating that again, as previously mentioned for air quality, mothers may be in better "toxicokinetic equilibrium" with environmental cadmium concentrations than their children.

Despite the fact that also differences in decreasing smoking habits have been identified as a key lifestyle factor driving the reduction in urinary cadmium over time (Tellez-Plaza et al., 2012), no significant effect of anti-tobacco legislation among different European countries on urinary cadmium levels was observed.

\subsection{Interpreting urinary cotinine data}

As there are well-documented aggregate EU-collected databases that provide an estimate of the strictness of (the implementation of) anti-smoking legislation, the relationship between urinary cotinine and national legislations could be assessed using the data provided by DG SANCO and an assessment from the Smokefree Partnership (see the links in Table 2 for more information on how this assessment was performed).

Table 5 provides an overview by DG SANCO of the strength of the smoke-free legislation in the DEMOCOPHES EU-countries (Status May 2011). Please note that Switzerland was not included in this analysis. Additionally, the Smokefree Partnership provided an overview of the 2010-status of legislation, which summarized the general legislation in one score: strong, limited, and weak (final column of Table 5). In this overview, information on the Swiss legislation was included, although it was stated that this may vary across Cantons. However, as a whole, the Swiss legislation was evaluated to be strong.

Relating the geometric mean urinary cotinine data in the DEMOCOPHES-countries for both mothers and children to the Smokefree Partnership overview of anti-smoking legislation (weak, limited, strong legislation) provides insight into the value of legislation for the levels urinary cotinine-levels of both children and mothers (Fig. 3). Following a non-parametric Kruskal-Wallis test on these three categories, significant differences among both the children's and the mother's cotinine levels were detected (respectively $p=0.039$ and $p=0.033$ ). According to subsequent Dunn's Multiple Comparison Test, significant differences existed only between the countries with weak and the countries with strong legislations for both mothers and children. From Fig. 3, it can also be noted that urinary cotinine levels in children from countries with weak legislative protection (respectively $1.53 \mu \mathrm{g} / \mathrm{g}$ creatinine) are about twice as high than with limited $(0.78 \mu \mathrm{g} / \mathrm{g}$ creatinine) and strong legislative protection to second-hand smoke $(0.67 \mu \mathrm{g} / \mathrm{g}$ creatinine). For mothers, the difference between weak and strong legislative protection was even larger, but it remains unclear to what extent the contribution of active smoking contributes to these differences in mothers. Performing the same analyses with the DG Sanco ranking provided very similar results (data not shown).

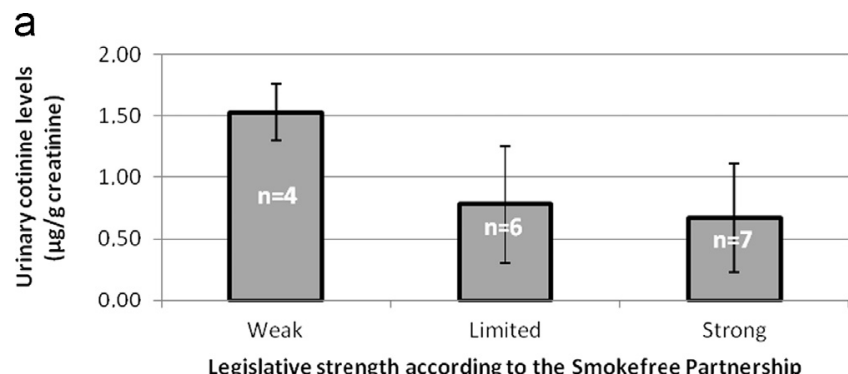

b

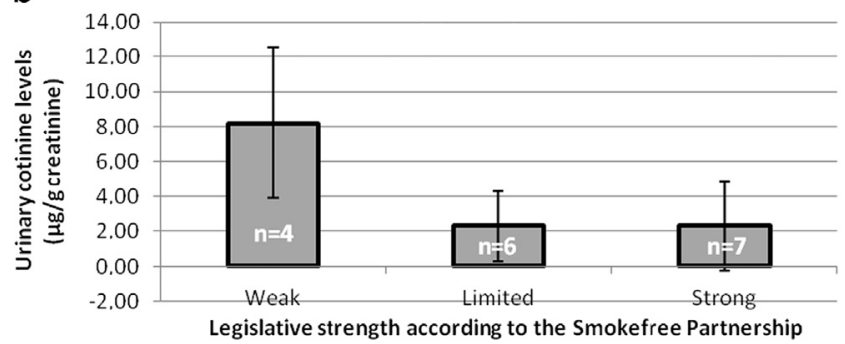

Fig. 3. Urinary cotinine levels in countries with differences in anti-smoking legislations for a) children and b) mothers (average \pm standard deviations).

Table 5

Overview of the smoke-free legislation in DEMOCOPHES-countries.

\begin{tabular}{|c|c|c|c|c|c|c|c|c|}
\hline & $\begin{array}{l}\text { General } \\
\text { workplace }\end{array}$ & $\begin{array}{l}\text { Enclosed } \\
\text { public } \\
\text { places }\end{array}$ & Restaurants & Bars & $\begin{array}{l}\text { Healthcare } \\
\text { facilities }\end{array}$ & $\begin{array}{l}\text { Education } \\
\text { facilities }\end{array}$ & $\begin{array}{l}\text { Public } \\
\text { transport }\end{array}$ & $\begin{array}{l}\text { Smokefree } \\
\text { Partnership } \\
\text { overview }\end{array}$ \\
\hline Belgium & + & + & + & - & + & ++ & ++ & Strong \\
\hline Cyprus & + & ++ & ++ & ++ & ++ & ++ & ++ & Limited \\
\hline Czech Republic & - & - & -- & -- & ++ & ++ & + & Weak \\
\hline Denmark & + & + & + & - & - & + & + & Limited \\
\hline Germany & + & + & - & - & + & + & + & Limited \\
\hline Hungary & - & - & -- & -- & - & ++ & - & Weak \\
\hline Ireland & ++ & ++ & ++ & ++ & - & ++ & ++ & Strong \\
\hline Luxembourg & + & ++ & + & - & + & ++ & + & Limited \\
\hline Poland & + & ++ & + & + & ++ & + & + & Limited \\
\hline Portugal & - & - & - & - & - & - & ++ & Weak \\
\hline Romania & + & + & - & - & ++ & + & ++ & Weak \\
\hline Slovakia & + & ++ & + & - & ++ & ++ & + & Limited \\
\hline Slovenia & + & + & + & + & ++ & ++ & + & Strong \\
\hline Spain & ++ & ++ & ++ & ++ & ++ & ++ & ++ & Strong \\
\hline Sweden & + & + & + & ++ & + & + & + & Strong \\
\hline Switzerland & \multicolumn{7}{|c|}{ Legislation varies by Canton - generally +} & Strong \\
\hline $\begin{array}{l}\text { United } \\
\text { Kingdom }\end{array}$ & ++ & ++ & ++ & ++ & ++ & ++ & ++ & Strong \\
\hline
\end{tabular}

++ : total ban on indoor smoking.

+ : ban on indoor smoking, while providing for separate enclosed smoking rooms/obligation for employer to protect employees.

- : partial ban on indoor smoking, e.g. smoking zones or exemptions for certain categories of venues.

- --: recommendations, suggestions, or no ban. 
In Scotland, implementation of a smoke-free legislation caused a $39 \%$ drop in salivary cotinine concentrations in primary school children (Akhtar et al., 2007). Even more, these authors also reported that if none of the parents smoked, and hence only external sources to second-hand smoke were a possible exposure route, increased legislative protection caused a 51\% fall in salivary cotinine levels. In England (Sims et al., 2012) and New York (Bauer et al., 2007), similar reductions in salivary cotinine levels from non-smoking adults were observed following strengthening of anti-tobacco legislation.

\section{External data to aid in interpreting mercury in hair}

\subsection{Interpreting mercury in hair from (sub)national datasets}

To aid in interpreting the potential differences in mercury content in hair, DEMOCOPHES implementing countries were asked to collect information on the presence of mercury in air and water as relevant exposure sources, and in aquatic food items (WHO and UNEP, 2008).

Mercury in air was reported by 4 out of 17 countries, with another 5 countries providing information that was not comparable to the others, or stated that no data were available (Table 4). For water as a possible exposure source, most countries reported measurements in both drinking water (as a source of direct exposure) and/or surface water (as an indicator of general environmental quality). All reported measurements of mercury in drinking water were below detection limits. For surface waters, two countries reported very small concentrations of mercury measurable in surface waters. The concentrations reported by other countries were all below the detection limit. No meaningful analysis could be performed on these data.

\subsection{Interpreting mercury in hair from aggregate EU-collected datasets}

From the CEIP, data on national emissions of mercury in air were retrieved from the WebDab-database (Table 2). However, correlating air emissions to mercury-levels in hair of children and mothers did not provide any significant relationships.

Additionally, data on specific mercury-emissions were collected from the E-PRTR database for both the urban and rural region. As data were available at NUTS-2 level, which is a more detailed geographical level than simply national averages, separate data were collected for the urban and rural areas. Following statistical analysis using Spearman rank correlation coefficients, no significant correlations between E-PRTR data and mercury-biomarkers for children and mothers were found. As fish consumption is by far the most important exposure metric for hair mercury, the lack of correlation between environmental compartments and mercury in hair was not a surprise.

\subsection{Fish consumption as an important source of mercury}

\subsection{1. (Sub)national data on fish consumption}

As fish consumption is a well-known exposure source of mercury in the general population (e.g. Airey, 1983; Bjornberg et al., 2003; EFSA, 2012b; Oken et al., 2012; Miklavčič et al., 2014), DEMOCOPHES implementing countries were asked to collect regional or national data on the amount of fish that is consumed (quantity of fish consumed) and also on the concentrations of mercury in fish (quality of fish consumed).

In total, 8 countries provided information on the quantity of aquatic organisms consumed annually. From Fig. 4, it can be seen from the size of the bars that there is almost an order of magnitude of difference between countries with low and high reported marine fish consumption. The average amount of fish consumed correlated highly significantly with mercury in hair of both children $(r=0.942, p<0.001)$ and their mothers $(r=0.898$, $p=0.002$ ).

With respect to data on the mercury contamination of aquatic organisms, there was a lot of variability in the amount and level of detail provided by the different countries. While some countries provided highly detailed, long lists of chemical analyses in over 25 different marine organisms, others reported mercury levels in unspecified freshwater fish, shellfish or marine fish. Averaging these data in three different categories (marine fish speciesshellfish species-freshwater species) resulted in significant correlations between the mercury-levels reported and mercury in hair of mothers and children for both marine fish and shellfish (Fig. 5). A graphical examination of the plots indicated that the mercury content of different aquatic organisms may contribute significantly to the total mercury dose, but the relationship was largely dominated by one country that reported both high fish consumption and high mercury content in fish species (Fig. 5). As could be expected, calculating a resulting mercury dose (quantity of fish consumed $\times$ mercury level in marine fish) resulted in highly significant correlations with mercury-levels in hair of both mothers and children (data not shown).

\subsubsection{Aggregate EU-collected data on fish consumption}

For the countries having implemented DEMOCOPHES, aggregate data on the consumption of aquatic organisms was collected from the Food and Agriculture Organization (FAO) FAOSTATdatabase (data from 2009; also see Table 2). This database provides extensive data on different groups of organisms, including aquatic plants, crustaceans, molluscs, demersal and pelagic marine fish, freshwater fish, and other aquatic products. Using these data, the relationship between the amount of marine organisms consumed and the biomarker values for mercury in hair of children and mothers was further explored (Fig. 6). Again using the Spearman rank correlation test, the relationship was highly significant for both children $(r=0.75, p<0.001)$ and mothers $(r=0.80, p<0.001)$.

\subsection{Interpreting DEMOCOPHES biomarker data}

At the start of the DEMOCOPHES project, some well-established hypotheses were identified to test the added value of collecting external data to assist in interpreting HBM data (e.g. the impact of environmental concentrations on urinary cadmium, or the impact of fish consumption on mercury in hair). Throughout both the (sub)national datasets and aggregate EU-collected datasets, a significant amount of relevant, high-quality data on environmental concentrations of cadmium or mercury in different environmental

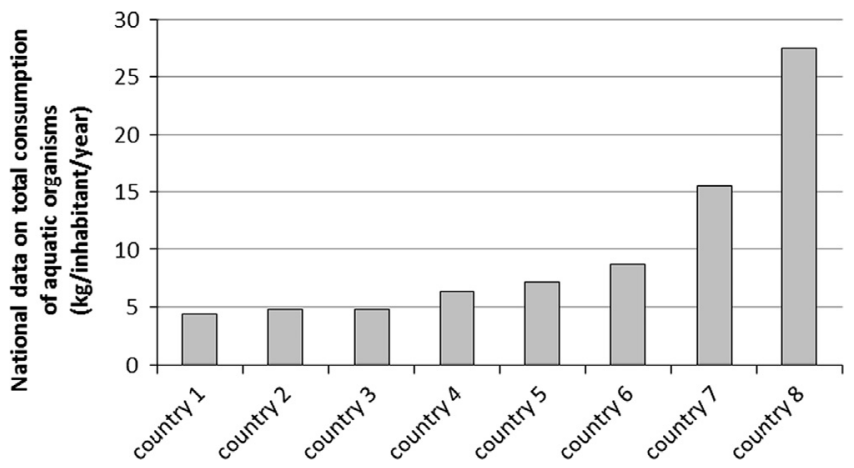

Fig. 4. Overview of reported national fish consumption data among different countries. 

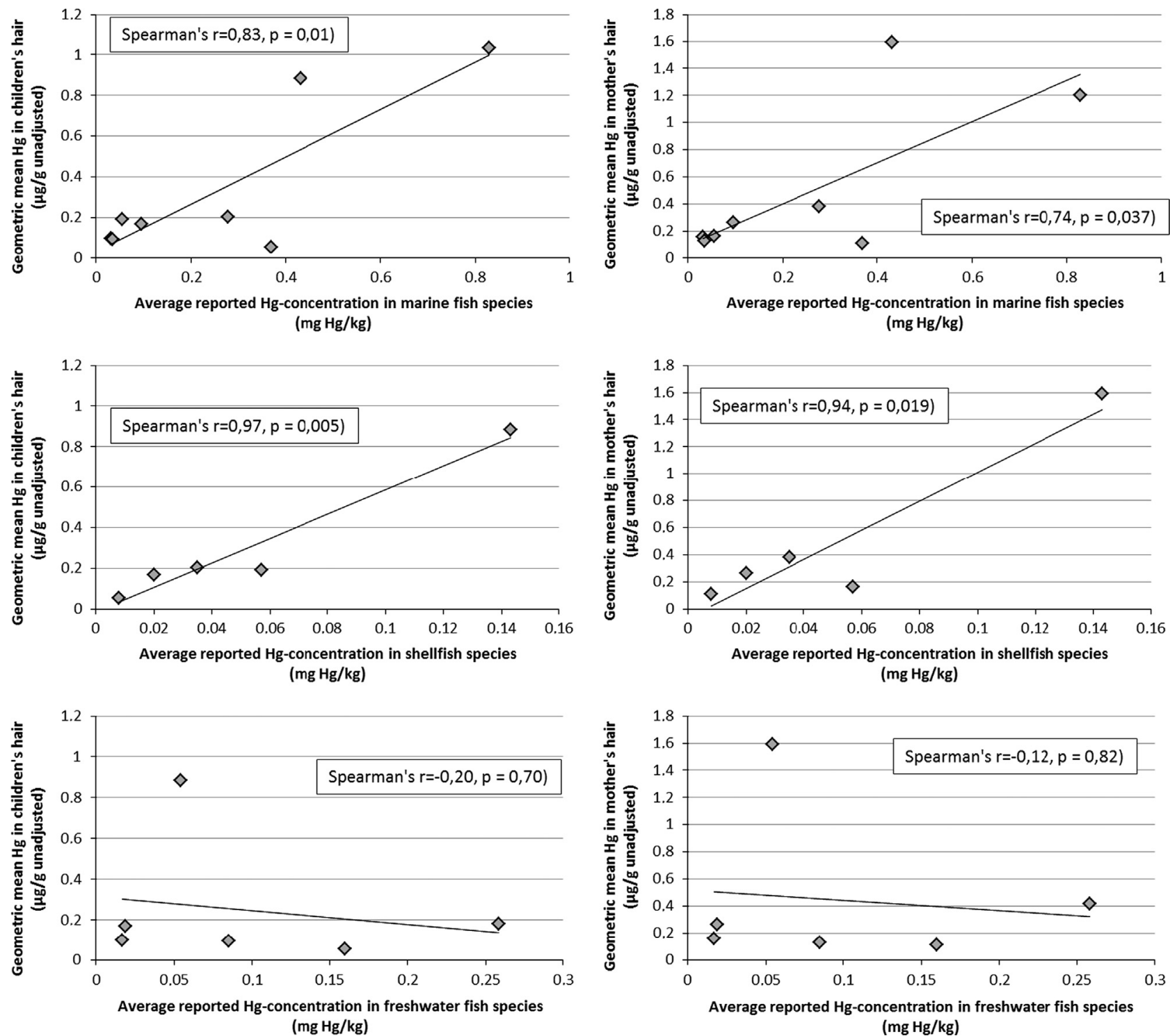

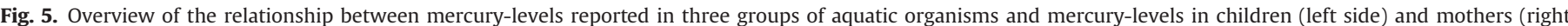
side).

compartments was collected. Heavy metals are probably one of the best-monitored environmental chemicals groups in Europe, and various regional, national and international agencies, monitoring and modelling campaigns, and research projects collect information on the presence of cadmium and mercury in various environmental compartments.

However, throughout our analyses, mainly borderline significant correlations $(0.05<p<0.10)$ were retrieved that aided in interpreting the presence of contaminants in different environmental compartments and biomonitoring values, particularly for cadmium. Partly, this was related to the fact that concentrations of contaminants in specific environmental compartments such as drinking and surface waters were very low, which is probably due to the stringent and easily enforceable environmental legislation, and frequent monitoring of contaminant levels in water bodies. All reported cadmium- and mercury-levels in drinking water were below detection limits, and also in surface waters, concentrations were mostly extremely low. For air and soils as potentially relevant environmental compartments, the analyses faced the problem of spatial heterogeneity. Levels in soil and in air often vary within small distances, and hence it is not easy to define accurate exposure levels of the urban and rural study populations participating in the DEMOCOPHES study.

\subsubsection{Food as an exposure source}

An additional important factor to interpret biomonitoring data is the potential intake through various food items. In order to fully interpret the contribution of food to biomarker levels, two types of information are required: i) the amount of a specific food item typically consumed and ii) the concentration of the specific contaminant in that food item. Only if both pieces of information are available on a representative level, can a relevant daily intake estimate be calculated.

Several countries reported large amounts of high quality data on the presence of cadmium and/or mercury in the various relevant food items (i.e. food quality), and for mercury in particular, also provided data on the amount of aquatic organisms consumed (i.e. food quantity). From the subsequent analyses, mainly the amount of aquatic organisms consumed was shown to influence the concentrations of mercury in hair across countries. For the food quality data, there was a trend that pointed towards 
a

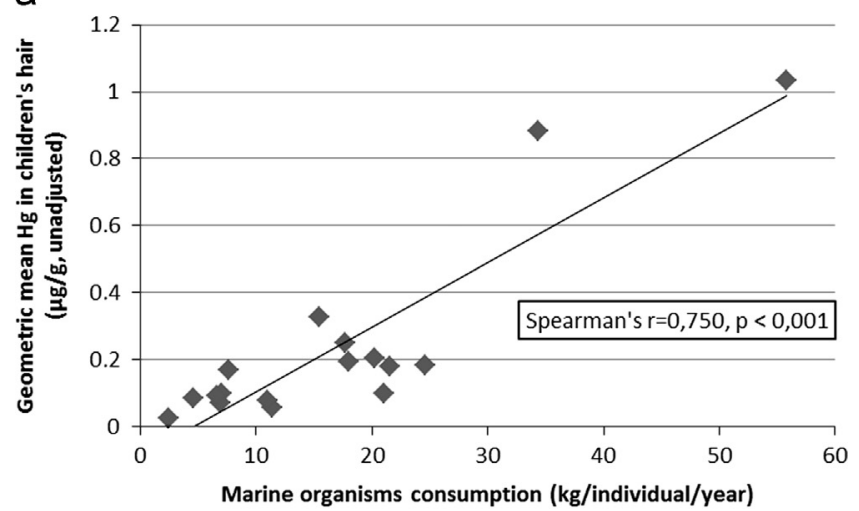

b

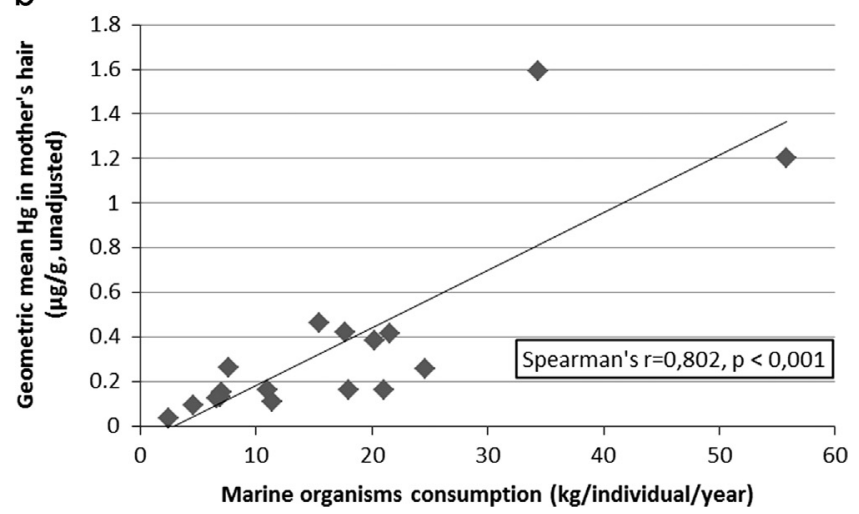

Fig. 6. Relationship between the total consumption of aquatic organisms as reported by FAO (most recent data from 2009) and the concentration of mercury in hair of a) children and b) mothers.

the confirmation that mercury concentrations in aquatic organisms have an impact on the concentrations of mercury in hair, yet this was not statistically significant. Unfortunately, there were only data available on the daily cadmium or mercury intake (i.e. food quality $\times$ food quantity) for 12 and 8 respectively of the 17 countries having implemented DEMOCOPHES, and particularly for cadmium intake, a large diversity among the different food items was included in the calculations. All these aspects together reduced the statistical power of the analyses considerably. Also aggregated EU-collected data from EFSA was only available for half of the countries having implemented the DEMOCOPHES study.

This lack of suitable data highlights the urgent need for a harmonized country and population representative database that provides data on both types and quantities of different foodstuffs consumed in Europe, and data on contaminants found in different food items. In February 2010, EFSA launched the EU-Menu project, a project aimed at harmonizing data collection on food consumption across Europe (EFSA, 2010). From 2012 to 2017, a rolling program will collect comparable and detailed information food consumption data across all countries and regions in the EU, which will hopefully tackle some of the issues our analyses also identified.

\subsubsection{The impact of legislations}

In the interpretation of urinary cotinine levels across different countries, exposure classification according to the strength of antismoking legislation differentiated countries with weak and strong anti-smoking legislations. Although we are aware that many influencing factors, e.g. gender, socio-economic status or migration, were not included in our analysis, our data strongly suggest that anti-smoking policy actions work effectively, and achieve their goals of reducing second-hand smoking in non-smokers. Particularly for children, which have no immediate individual exposure to tobacco products, it is highly valuable to measure what the impact of strong legislation is on exposure, and particularly to understand that weak anti-smoking legislation results in an almost threefold higher average urinary cotinine level compared to children that are protected by strong anti-smoking laws. It was rather surprising that even for mothers, with much higher and more variable urinary cotinine levels, the same significant association with anti-smoking legislation was observed.

\section{Conclusions}

In general, 13 countries having implemented DEMOCOPHES provided high-quality external data that was relevant for interpretation purposes, although some data were not available for reporting or were not in line with the data from other countries. This reduced the statistical power of our study. Nonetheless, several significant correlations between external data and biomarker values were observed, including the relationship between fish consumption and mercury in hair, the strength of antismoking legislation to urinary cotinine levels, and indications that urinary cadmium levels were associated with environmental quality and food quality.

This study showed that it is certainly possible to collect high quality external data to aid in biomarker interpretation, but there is room for improvement such as more targeted data collection or extraction of data from databases that are directly related to the environment or life style of the study participants. This however would require discussion on privacy aspects. These first results are however very promising and already show the larger picture that can be obtained by combining human biomonitoring and environmental data to provide synergistic value for (the evaluation of) evidence-informed policy making. It should be kept in mind that human biomonitoring is not a stand-alone instrument, and the integration of HBM into the broader field of environmental quality, health or dietary surveys is helpful to further extend the use all environmental monitoring systems.

\section{Proposed reviewers}

- Denis Sarigiannis (Aristotle University of Thessaloniki, Greece): d.a.sarigiannis@gmail.com

- Sean Hays (Summit Toxicology, USA): shays@summittoxicology.com

- Nadine Fréry (INvS, France): n.frery@invs.sante.fr

- Philipp Hohenblum (EPA, Austria): philipp.hohenblum@umweltbundesamt.at

All these reviewers are very knowledgeable in the field of HBM interpretation, and did not participate in the COPHES/DEMOCOPHES case study.

\section{Acknowledgments and funding sources}

We wish to thank the European Commission, Belgium, DG for Research and Innovation (RTD), who is funding COPHES in the 7th Framework Programme (No. 244237). DEMOCOPHES (LIFE09 ENV/BE/ 000410) received 50\% funding through the LIFE + financial instrument of the European Union (DG ENV), as well as 50\% through funding received from the DEMOCOPHES partners (http:// www.eu-hbm.info/DEMOCOPHES/project-partners). More information about the COPHES/DEMOCOPHES twin projects can be found at 
www.eu-hbm.info and the other papers in this Special Issue. Finally, we would particularly like to thank all the mothers and children who so generously participated in this study. All data were collected following the guidelines of national ethical committees.

\section{References}

Airey, D., 1983. Total mercury concentrations in human hair from 13 countries in relation to fish consumption and location. Sci. Total Environ. 31, 157-180.

Akhtar, P.C., Currie, D.B., Currie, C.E., Haw, S.J., 2007. Changes in child exposure to environmental tobacco smoke (CHETS) study after implementation of smoke-free legislation in Scotland: national cross sectional survey. Br. Med. J. 335, 545-549.

Allwright, S., Paul, G., Greiner, B., Mullaly, B.J., Pursell, L., Kelly, A., Bonner, B., D’Eath, M. McConnell, B., McLaughlin, J.P., O’Donovan, D., O'Kane, E., Perry, I.J., 2005. Legislation for smoke-free workplaces and health of bar workers in Ireland: before and after study. Br. Med. J. 331, 1117.

Bauer, U., Juster, H., Hyland, A., Farrelly, M., Engelen, M., Weitzenkamp, D., Repace J., Babb, S., 2007. Reduced secondhand smoke exposure after implementation of a comprehensive statewide smoking ban - New York, June 24 2003, June 30, 2004. Morb. Mortal. Wkly. Rep. 56, 705-708.

Becker, K., Seiwert, M., Casteleyn, L., Joas, R., Joas, A., Biot, P., Aerts, D., Castano, A., Esteban, M., Angerer, J., Koch, H.M., Schoeters, G., Den Hond, E., Sepai, O., Exley, K., Knudsen, L.E., Horvat, M., Bloemen, L., Kolossa-Gehring, M., 2014. A systematic approach for designing a HBM pilot study for Europe. Int. J. Hyg. Environ. Health 217, 312-322.

Becker, K., Kolossa-Gehring, M., Seiwert, M., Casteleyn, L., Polcher, A., Sepai, O., Knudsel, L., Schoeters, G., Smolders, R., Castano, A., Jiminez Guerrero, J.A., Horvat, M., Bloemen, L., Angerer, J., Koch, H., Joas, R., 2011. Exploring exposure in 27 countries in a European human biomonitoring study-Cophes. Epidemiology 22, S230-S231.

Bevan, R., Angerer, J., Cocker, J., Jones, K., Koch, H.M., Sepai, O., Schoeters, G., Smolders, R., Levy, L., 2012. Framework for the development and application of environmental biological monitoring guidance values. Regul. Toxicol. Pharmacol. 63, 453-460.

Bilau, M., De Henauw, S., Schroijen, C., Bruckers, L., Den Hond, E., Koppen, G., Matthys, C., Van De Mieroop, E., Keune, H., Baeyens, W., Nelen, V., Van Larebeke, N., Willems, J.L., Schoeters, G., 2009. The relation between the estimated dietary intake of PCADMIUMD/Fs and levels in blood in a Flemish population (50-65 years). Environ. Int. 35, 9-13.

Bjornberg, K.A., Vahter, M., Petersson-Grawe, K., Glynn, A., Cnattingius, S., Darnerud, P.O., Atuma, S., Aune, M., Becker, W., Berglund, M., 2003. Methyl mercury and inorganic mercury in Swedish pregnant women and in cord blood: influence of fish consumption. Environ. Health Perspect. 111, 637-641.

Burger, J., Stern, A.H., Gochfeld, M., 2005. Mercury in commercial fish: optimizing individual choices to reduce risk. Environ. Health Perspect. 113, 266-271.

Calafat, A., 2012. The U.S. National Health and Nutrition Examination Survey and human exposure to environmental chemicals. Int. J. Hyg. Environ. Health 215, 99-101.

Cerna, M., Krskova, A., Cejchanova, M., Spevackova, V., 2012. Human biomonitoring in the Czech Republic: an overview. Int. J. Hyg. Environ. Health 215, 109-119.

Den Hond, E., Govarts, E., Willems, H., Smolders, R., Schoeters, G., 2012. Human biomonitoring in children and mothers-European analysis. COPHES Deliv. D4 (5b) (189 pp.).

Dong, Z., Hu, J., 2012. Development of lead source-specific exposure standards based on aggregate exposure assessment: Bayesian inversion from biomonitoring information to multipathway exposure. Environ. Sci. Technol. 46, 1144-1152.

EFSA, 2009. Scientific opinion of the panel on contaminants in the food chain on a request from the European Commission on cadmium in food. EFSA J. 980, 1-139.

EFSA, 2010. Declaration of the Advisory Forum on the Pan-European Food Consumption Survey-what's on the menu in Europe. Declaration of EU member states on the EU-menu, available at: 〈http://www.efsa.europa.eu/en/ eumenu/docs/eumenudeclarationen.pdf).

EFSA, 2012a. Cadmium dietary exposure in the European population. EFSA J. 10, 2551.

EFSA Panel on Contaminants in Food Chain, 2012b. Scientific opinion on the risk for public health related to the presence of mercury and methylmercury in food. EFSA J. 10, 2985.

Esteban, M., Ruiz-Moraga, M., Pérez-Gómez, B., Castaño, A., demás componentes del grupo BIOAMBIENT.ES, 2013. Aspectos prácticos de la fase pre-analítica del estudio de biovigilancia BIOAMBIENT.ES. Gac. Sanit. 27, 77-80.

Frery, N., Vandentorren, S., Etchevers, A., Fillol, C., 2012. Highlights of recent studies and future plans for the French human biomonitoring (HBM) programme. Int. J. Hyg. Environ. Health 215, 127-132.

Haines, D.A., Murray, J., 2012. Human biomonitoring of environmental chemicalsearly results of the 2007-2009 Canadian Health Measures Survey for males and females. Int. J. Hyg. Environ. Health 215, 133-137.

Haug, L.S., Huber, S., Becher, G., Thomsen, C., 2011. Characterisation of human exposure pathways to perfluorinated compounds-comparing exposure estimates with biomarkers of exposure. Environ. Int. 37, 687-693.
Jarup, L., Akesson, A., 2009. Current status of cadmium as an environmental health problem. Toxicol. Appl. Pharmacol. 238, 201-208.

Joas, R., Casteleyn, L., Biot, P., Kolossa-Gehring, M., Castano, A., Angerer, J., Schoeters, G. Sepai, O., Knudsen, L.E., Joas, A., Horvat, M., Bloemen, L., 2012. Harmonised human biomonitoring in Europe: activities towards an EU HBM framework. Int. J. Hyg. Environ. Health 215, 172-175.

Johansson, A., Halling, A., Hermansson, G., Ludvigsson, J., 2005. Assessment of smoking behaviours in the home and their influence on children's passive smoking: development of a questionnaire. Ann. Epidemiol. 15, 453-459.

Julin, B., Vahter, M., Amzal, B., Wolk, A., Berglund, M., Akesson, A., 2011. Relation between dietary cadmium intake and biomarkers of cadmium exposure in premenopausal women accounting for body iron stores. Environ. Health 10, 105.

Karagas, M.R., Choi, A.L., Oken, E., Horvat, M., Schoeny, R., Kamai, E., Cowell, W., Grandjean, P., Korrick, S., 2012. Evidence on the human health effects of low-level methylmercury exposure. Environ. Health Perspect. 120, 799-806.

Kolossa-Gehring, M., Becker, K., Conrad, A., Schröter-Kermani, C., Schulz, C., Seiwert, M., 2012. Environmental surveys, specimen bank and health related environmental monitoring in Germany. Int. J. Hyg. Environ. Health 215, 120-126.

Mareckova, K., Wankmueller, R., Whitinig, R., Pinterits, M., 2012. Inventory Review 2012: review of emission data reported under the LRTRAP Convention and NEC Directive (Technical Report EMEP-CEIP 1/2012). (74 pp.).

Miklavčič, A., Casetta, A., Snoj Tratnik, J., Mazej, D., Krsnik, M., Mariuz, M., Sofianou, K., Špirić, Z., Barbone, F., Horvat, M., 2013. Mercury, arsenic and selenium exposure levels in relation to fish consumption in the Mediterranean area. Environ. Res. 120, 7-17.

Miklavčič, A., Kocman, D., Horvat, M., 2014. Human mercury exposure and effects in Europe. Environ. Toxicol. Chem. 33, 1259-1270.

Oken, E., Choi, A.L., Karagas, M.R., Marien, K., Rheinberger, C.M., Schoeny, R., Sunderland, E., Korrick, S., 2012. Which fish should I eat? Perspectives influencing fish consumption choices. Environ. Health Perspect. 120, 790-798.

Omarova, A., Philips, C.J.C., 2007. A meta-analysis of literature data relating to the relationships between cadmium intake and toxicity indicators in humans. Environ. Res. 103, 432-440.

Paustenbach, D., Galbraith, D., 2006. Biomonitoring and biomarkers: exposure assessment will never be the same. Environ. Health Perspect. 114, 1143-1149.

Pino, P., Walter, T., Oyarzun, M.J., Burden, M.J., Lozoff, B., 2004. Rapid drop in infant blood lead levels during the transition to unleaded gasoline use in Santiago, Chile. Arch. Environ. Health 59, 182-187.

Pleil, J.D., Stiegel, M.A., Madden, M.C., Sobus, J.R., 2011. Heat map visualization of complex environmental and biomarker measurements. Chemosphere 84, 716-723.

Pérez-Gómez, B., Pastor-Barriuso, R., Cervantes-Amat, M., Esteban, M., Ruíz-Moraga, M. Aragonés, N., Pollán, M., Navarro, C., Calvo, E., Román, J., López-Abente, G., Castaño, A., BIOAMBIENT.ES, 2013. BIOAMBIENT.ES study protocol: rationale and design of a cross-sectional human biomonitoring survey in Spain. Environ. Sci. Pollut. Res. Int. 20, 1193-1202.

Sarigiannis, D.A., Hansen, U., 2012. Considering the cumulative risk of mixtures of chemicals-a challenge for policy makers. Environ. Health 11 (Suppl 1), S18.

Schnaas, L., Rothenberg, S.J., Flores, M.-F., Martinez, S., Hernandez, C., Osorio, E. Perroni, E., 2004. Blood lead secular trend in a cohort of children in Mexico City (1987-2002). Environ. Health Perspect. 112, 1110-1115.

Schoeters, G., Den Hond, E., Colles, A., Loots, I., Morrens, B., Keune, H., Bruckers, L. Nawrot, T., Sioen, I., De Coster, S., Van Larebeke, N., Nelen, V., Van de Mieroop, E., Vrijiens, J., Croes, K., Goeyens, K., Baeyens, W., 2012. Concept of the Flemish human biomonitoring programme. Int. J. Hyg. Environ. Health 215, 102-108.

Sims, M., Mindell, J.S., Jarvis, M.J., Feyerabend, C., Wardle, H., Gilmore, A., 2012. Did smokefree legislation in England reduce exposure to secondhand smoke among non-smoking adults? Cotinine analysis from the Health Survey for England. Environ. Health Perspect. 120, 425-430.

Smolders, R., Caeyers, T., Den Hond, E., Govarts, E., Koppen, G., Willems, H., Schoeters, G., 2012. Collecting regional data for the interpretation of (DEMO) COPHES biomarker data. COPHES Deliv. 4 (2), 32.

Smolders, R., Koppen, G., Schoeters, G., 2007. Translating biomonitoring data into risk management and policy implementation options for a European network on human biomonitoring. Environ. Health 7 (Suppl 1), S2.

Smolders, R., Schramm, K.-W., Stenius, U., Grellier, J., Khan, A., Trnovec, T., Sram, R., Schoeters, G., 2009. A review on the practical application of human biomonitoring in integrated environmental health impact assessment. J. Toxicol. Environ. Health B 12, 107-123.

Tellez-Plaza, M., Navas-Acien, A., Caldwell, K.L., Menke, A., Muntner, P., Guallar, E., 2012. Reduction in cadmium exposure in the United States population, 1988-2008: the contribution of declining smoking rates. Environ. Health Perspect. 120, 204-209.

Vromman, V., Waegeneers, N., Cornelis, C., De Boosere, I., Van Holderbeke, M. Vinkx, C., Smolders, R., Huyghebaert, A., Pussemier, L., 2010. Dietary cadmium intake by the Belgian adult population. Food Addit. Contam. A 27, 1665-1673.

WHO and UNEP. 2008. Guidance for identifying populations at risk from mercury exposure. 176 pp. Available at: 〈http://www.who.int/foodsafety/publications/ chem/mercuryexposure.pdf $\rangle$. 